\title{
CENÁRIOS HIDROCLIMÁTICOS FUTUROS (2011-2040) PARA A REPRESA DE PARAIBUNA, SP, BRASIL: SUBSÍDIOS PARA A TRANSPOSIÇÃO ENTRE BACIAS HIDROGRÁFICAS
}

\author{
FUTURE HYDROCLIMATE SCENARIOS (2011-2040) FOR THE PARAIBUNA DAM, SP, \\ BRAZIL: SUBSIDIES FOR TRANSPOSITION BETWEEN RIVER BASINS
}

\author{
Rodrigo César da SILVA, Gilberto FISH \\ Universidade de Taubaté. Rua Quatro de Março, 432, Taubaté - SP. Emails: rodrigo.peb@gmail.com; fisch.gilberto@gmail.com

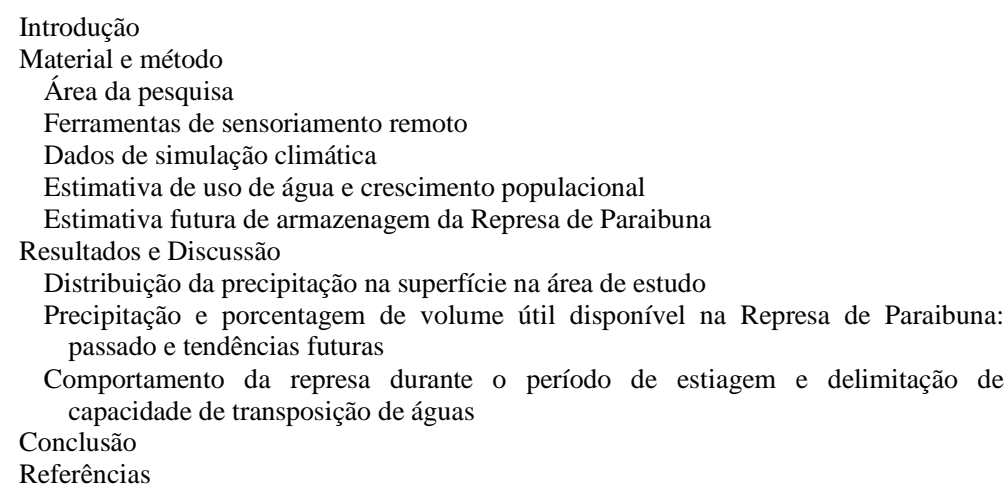

RESUMO - A crise hídrica em São Paulo nos anos de 2014-2015 gerou conflitos pelo uso da água, visto que os totais de precipitação abaixo da normal climatológica impactaram os níveis dos reservatórios que abastecem a região. Neste contexto, a transposição das águas da bacia hidrográfica do rio Paraíba do Sul para o Sistema Cantareira, que abastece a Região Metropolitana de São Paulo foi proposta pelas autoridades para mitigar os impactos desta crise e abastecer sua população, sendo necessário analisar se a transposição proposta atenderá à sua demanda. Para investigar as condições futuras de quantidade de água da represa de Paraibuna, foram utilizados dados de simulação climática do modelo atmosférico global HadCM3/Eta, considerando o cenário SRES (Special Report on Emission Scenarios) A1B do IPCC (Intergovernmental Panel on Climate Change), para os períodos passado (1961-1990) e futuro (2011-2040). Os resultados estimam que até 2040 aumentará a demanda em $123 \%$ pelas águas da bacia do Paraíba do Sul, e em apenas $40 \%$ dos anos poderá ocorrer a transferência de água entre as bacias hidrográficas, sendo que na década de 2030 apenas em três anos esta transposição será viável. Isto demonstra a baixa efetividade da proposta e coloca em evidência a transposição entre bacias hidrográficas como solução para a crise de abastecimento na região.

Palavras-chave: Crise hídrica, Precipitação, Simulação climática, Vale do Paraíba.

ABSTRACT - The water crisis in São Paulo in the years 2014-2015 generated conflicts over the use of water since the totals of precipitation below the climatological norm impacted the levels of the reservoirs that supply the region. In this context, the transposition of the waters of the Paraíba do Sul river basin into the Cantareira System, which supplies the Metropolitan Region of São Paulo, was proposed by the authorities to mitigate the impacts of this crisis and supply their population, and it is necessary to analyze whether the proposed transposition will meet your demand. In order to investigate the future conditions of water quantity of the Paraibuna dam, data were used to simulate the global atmospheric model HadCM3/Eta, considering the IPCC (Intergovernmental Panel on Climate Change) scenario SRES (Special Report on Emission Scenarios) A1B, for the past (19611990) and future (2011- 2040). The results estimate that by 2040 the demand for water in the Paraíba do Sul basin will increase by $123 \%$, and in only $40 \%$ of the years water transfer between the river basins may occur, and in the 2030s only in three years, this transposition will be feasible. This demonstrates the low effectiveness of the proposal and highlights the transposition between river basins as a solution to the supply crisis in the region. Keywords: Water crisis, precipitation, climate simulation, Vale do Paraíba.

\section{INTRODUÇÃO}

O período de 2014-2015 foi marcado por uma grande seca na região sudeste, em especial no estado de São Paulo, sendo esta a mais grave dos últimos 84 anos (INPE, 2015). Esta seca impactou diretamente os níveis dos reservatórios que abastecem duas das principais regiões metropolitanas do Brasil, São Paulo e Rio de Janeiro, gerando conflitos pelo uso da água da bacia hidrográfica do rio Paraíba do Sul. Desta forma, a análise atual e a investigação das tendências futura de precipitação e os impactos que estas exercem sobre a disponibilidade hídrica da região torna-se necessária, uma vez que tal escassez gera problemas para o sistema de abastecimento da população, disponibilidade para irrigação, geração de energia elétrica e para as atividades industriais da região do Vale do Paraíba.

Neste mesmo período, outras áreas do planeta também enfrentaram severa escassez hídrica, a exemplo do estado da Califórnia, nos Estados Unidos. A seca dos anos 2012-2014 foi a mais severa do último milênio segundos estudos paleoclimáticos, entretanto não foi a única de três anos ininterruptos, indicando que 
apesar dos índices de chuva na Califórnia estarem abaixo da média histórica, o fato das temperaturas médias na região estarem 36\% acima da normal climatológica contribuiu para o agravamento da crise hídrica, sendo que a combinação entre altas temperaturas e precipitações abaixo da média, porém com índices não excepcionalmente baixos, conduziu ao caso de maior aridez na Califórnia nos últimos 1200 anos (GRIFFIN \& ANCHUKAITIS, 2014).

Segundo Marengo et al. (2015a), durante a maior parte da estação chuvosa de 2014 ocorreu índices de precipitação inferiores à média histórica para a região do sudeste brasileiro, causado por uma anomalia atmosférica denominada bloqueio atmosférico, que se materializa por uma zona de alta pressão na região do Brasil central bloqueando a chegada de umidade vinda da Amazônia, o que prejudica o desenvolvimento de um dos principais sistemas que geram chuvas na região, a Zona de Convergência do Atlântico Sul, e descartando a possibilidade de influência do desmatamento da Amazônia e da transferência da umidade da Amazônia para o Sudeste como fatores para os baixos índices de precipitação.

Este anticiclone mencionado permaneceu presente no sudeste brasileiro durante 45 dias no ano de 2014 (entre janeiro e meados do mês de fevereiro), gerando índices de precipitação na região do sistema Cantareira de apenas 87,9 mm, $87 \%$ abaixo da média histórica para a região, sendo o acumulado de precipitação nos meses de dezembro de 2013 e janeiro e fevereiro de 2014 (período chuvoso) foi de apenas $32,8 \%$ se comparado a normal climatológica, impactando diretamente o volume de água disponível no reservatório do Sistema Cantareira e nos demais reservatórios da região sudeste (MARENGO et al., 2015b).

Segundo Oliveira Filho (2015), com baixos volumes de águas nos reservatórios da bacia hidrográfica do rio Paraíba do Sul e do Sistema Cantareira houve a deflagração de uma crise política e de governança entre os estados de São Paulo, Rio de Janeiro e Minas Gerais. Estes estados compartilham a rede hidrográfica e entraram em conflitos pela disputa do uso das águas em detrimento de suas respectivas demandas. Uma das soluções encontrada para esta crise hídrica foi a proposição da transposição das águas da bacia hidrográfica do rio Paraíba do Sul para o Sistema Cantareira, que abastece a Região Metropolitana de São Paulo.

O termo transposição significa transferir, modificar algo de lugar (ANJOS et al., 1999), logo transposição implica a transferência de águas entre duas bacias hidrográficas distintas. Wilson et al. (2017) ao analisar o caso da transposição de água sul-norte na China (China's South-North WaterTransfer Project SNWTP), que transfere água entre as bacias hidrográficas do rio Yangtze e Amarelo, afirma que esta transferência de água é de $18,5 \mathrm{~km}^{3}$ anual atualmente e poderá atingir $27,8 \mathrm{~km}^{3} \mathrm{em}$ pouco tempo, o que caracteriza a obra como uma das maiores tentativas de transferência de águas entre bacias hidrográficas que se tem conhecimento. Os autores apontam que apesar de décadas de estudos há muitas incertezas quanto aos impactos ambientais, econômicos e sociais referentes a este projeto. Os ganhos econômicos referentes à transposição variam de forma muito ampla sem uma garantia de sucesso econômico em nível nacional e incidam que em longo prazo é muito provável que o projeto SNWTP não seja ambientalmente sustentável (WILSON et al., 2017).

Gohari et al. (2013), ao analisar a bacia hidrográfica do rio Zayandeh-Rud, uma das mais importantes da região central do Irã, aponta que a gestão de uma bacia hidrográfica deve possuir uma abordagem holística devido à complexidade dos sistemas socioeconômico e biofísicos em seu interior, indicando que a transposição de águas entre bacias hidrográficas aliviam os sintomas de estresse hídrico de forma temporária, sendo que a escassez reaparece em longo prazo visto que a falsa sensação de abundância hídrica estimula a migração e práticas agrícolas inadequadas que desperdiçam água. Apontam ainda que a gestão das bacias se tornam ainda mais complexas se considerados os danos socioeconômicos e nos ecossistemas em longo prazo.

Matosso (2009) expõe que para haver sucesso nos casos de transposição de água, as populações envolvidas e afetadas por tais obras devem ser consultadas e a efetivação da troca de águas entre bacias hidrográficas deve se justificar em função das áreas receptoras possuírem recursos hídricos insuficientes para a demanda local, índices de precipitação inferior 
àqueles necessários para suprir o abastecimento humano, insuficiência hídrica para as necessidades agrícolas locais e de criação de gado, além das reservas de águas subterrâneas serem incapazes de atender a demanda local.

Carvalho (2005) aponta que a irregularidade temporal de precipitações e disponibilidade de recursos hídricos são os grandes motivadores de transposição de água entre bacias hidrográficas, apontando que ações antrópicas e suas consequências também podem desencadear a necessidade de transferência de águas tais como chuvas ácidas que poluem grandes reservatórios de água, poluição orgânica e inorgânica que tornam as águas de rios impróprios para o consumo humano, o desmatamento de matas ciliares, o avanço do processo de urbanização, mineração dentre outros.

Por fim, outro aspecto que altera os regimes de precipitação e a disponibilidade de recursos hídricos são as mudanças climáticas globais, ocasionado pela emissão excessiva de gases do efeito estufa que tem modificado a composição química da atmosfera, o que impacta diretamente o clima, podendo potencializar tendências de secas e estiagem, alterar o regime de chuvas e ainda aumentar a evaporação devido ao aumento médio da temperatura (IPCC, 2013). Os fatos mencionados tornam-se empecilhos para a gestão dos recursos hídricos, pois altera o padrão climático local e seu comportamento, gerando a necessidade de um entendimento dessas mudanças e de suas consequências para o futuro dos reservatórios que abastecem as duas principais regiões metropolitanas do país, demando desta forma políticas de conservação e governança dos recursos hídricos (JACOBI et al., 2015).

Sendo assim, o objetivo desta pesquisa é relacionar a quantidade de precipitação e o armazenamento de água na represa de Paraibuna para, a partir de dados de simulação climática do futuro, verificar os índices de precipitação, a capacidade de água armazenada e as condições futuras de transposição de águas da bacia hidrográfica do rio Paraíba do Sul para o Sistema Cantareira. Para tanto, a represa de Paraibuna será a referência de capacidade de armazenamento (ainda que a transposição ocorra diretamente da represa de Jaguari), justificado pelo fato que as represas de Paraibuna, Jaguari, Santa Branca (SP) e Funil (RJ) formam um reservatório equivalente, ou seja, um estoque conjunto de água. A represa de Paraibuna corresponde por $70,5 \%$ do volume útil de água disponível na bacia hidrográfica do rio Paraíba do Sul (ANA, 2017), sendo impossível ocorrer a transposição com baixos índices de armazenamento nesta represa.

\section{MATERIAL E MÉTODO}

\section{Área de pesquisa}

A pesquisa teve como referência a represa de Paraibuna (Figura 1), localizada nos municípios de Paraibuna, Redenção da Serra e Natividade da Serra e ao longo das bacias hidrográficas dos rios Paraitinga e Paraibuna. Esta represa foi formada a partir do represamento dos rios supracitados que formam um único corpo.

A área em estudo está inserida na bacia hidrográfica do rio Paraíba do Sul, que possui uma área total de aproximadamente $57.000 \mathrm{~km}^{2}$, sendo $13.605 \mathrm{~km}^{2}$ no Estado de São Paulo, $22.600 \mathrm{~km}^{2}$ no Estado do Rio de Janeiro e $20.500 \mathrm{~km}^{2}$ no Estado de Minas Gerais. Seu principal rio é o Paraíba do Sul, que se forma pela confluência dos rios Paraitinga e Paraibuna, possuindo uma extensão de aproximadamente $1.180 \mathrm{~km}$ (MARENGO \& ALVES, 2005). A represa de Paraibuna possui a maior capacidade de armazenamento total de água dentre as represas existentes na bacia do rio Paraíba do
Sul, com $4.740 \mathrm{hm}^{3}$, e volume útil de $2.636 \mathrm{hm}^{3}$ (CEZÁRIO, 2005).

\section{Ferramentas de sensoriamento remoto}

O monitoramento da superfície da represa de Paraibuna foi realizado por meio de cenas dos satélites Landsat 5 e 8, obtidas da página da U.S Geological Survey, utilizando-se da ferramenta Earth Explorer, pelo endereço eletrônico http://earthexplorer.usgs.gov/. As cenas selecio-nadas abrangeram o período entre 2010 a 2017, buscando imagens com ausência de nuvens, o que acarretaria prejuízos na mensuração da área em estudo. As cenas foram classificadas com auxílio dos softwares Quantum GIS 2.18 (Sistema de Informação Geográfica) e SPRING 5.2.5 (Sistema de Processamento de Informações Geográficas). Outras metodologias para monitoramento de superfícies de represas e estimativas da relação cota-volume pode ser observado em Collischonn \& Clark (2016). 


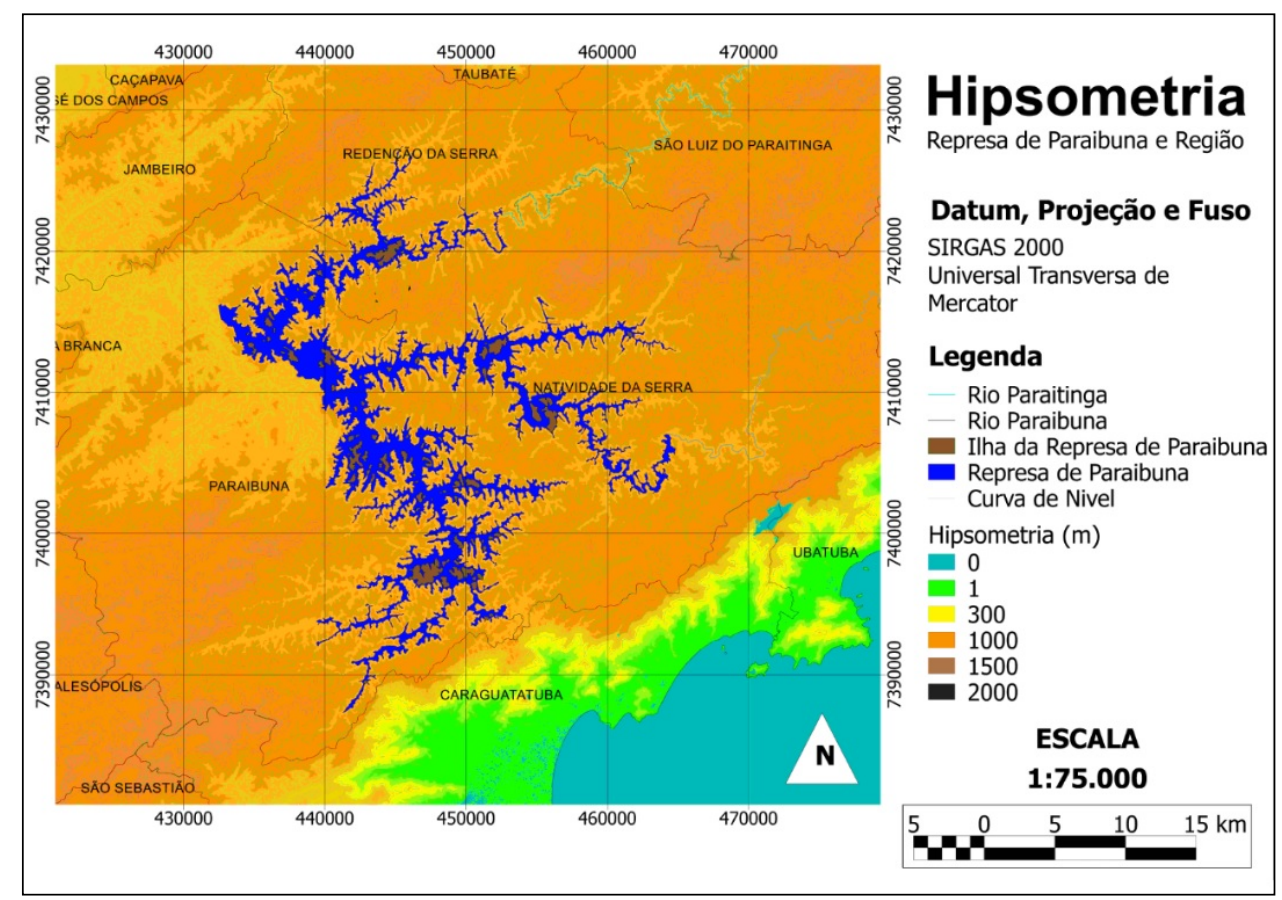

Figura 1. Mapa hipsométrico da região, com localização da Represa de Paraibuna.

\section{Dados de simulação climática}

Os dados de simulação climática foram obtidos do Modelo Acoplado OceanoAtmosfera HadCM3, desenvolvido no Hadley Centre do Reino Unido e simulados através do modelo regional Eta. A grade de resolução utilizada na pesquisa foi $20 \times 20 \mathrm{~km}$, sendo usado o cenário A1B como referência. Segundo Santos \& Fisch (2016), este cenário é equivalente ao atualmente utilizado pelo IPCC de RCP 4.5 (Representative Concentration Pathway). Estes mesmos autores fazem uma descrição detalhada do modelo utilizado e dos dados obtidos, bem como das incertezas envolvidas.

As grades de simulação utilizadas foram demarcadas com a numeração de 1 a 12 (Figura 2). A chuva que ocorreu na quadrícula 11 foi desprezada por não ter sido considerada como um contribuinte significativo para 0 reservatório. Os dados de precipitação gerados pelo modelo de simulação climática são homogêneos em toda a área simulada, ou seja, não há variação de precipitação dentro dos pontos simulados.

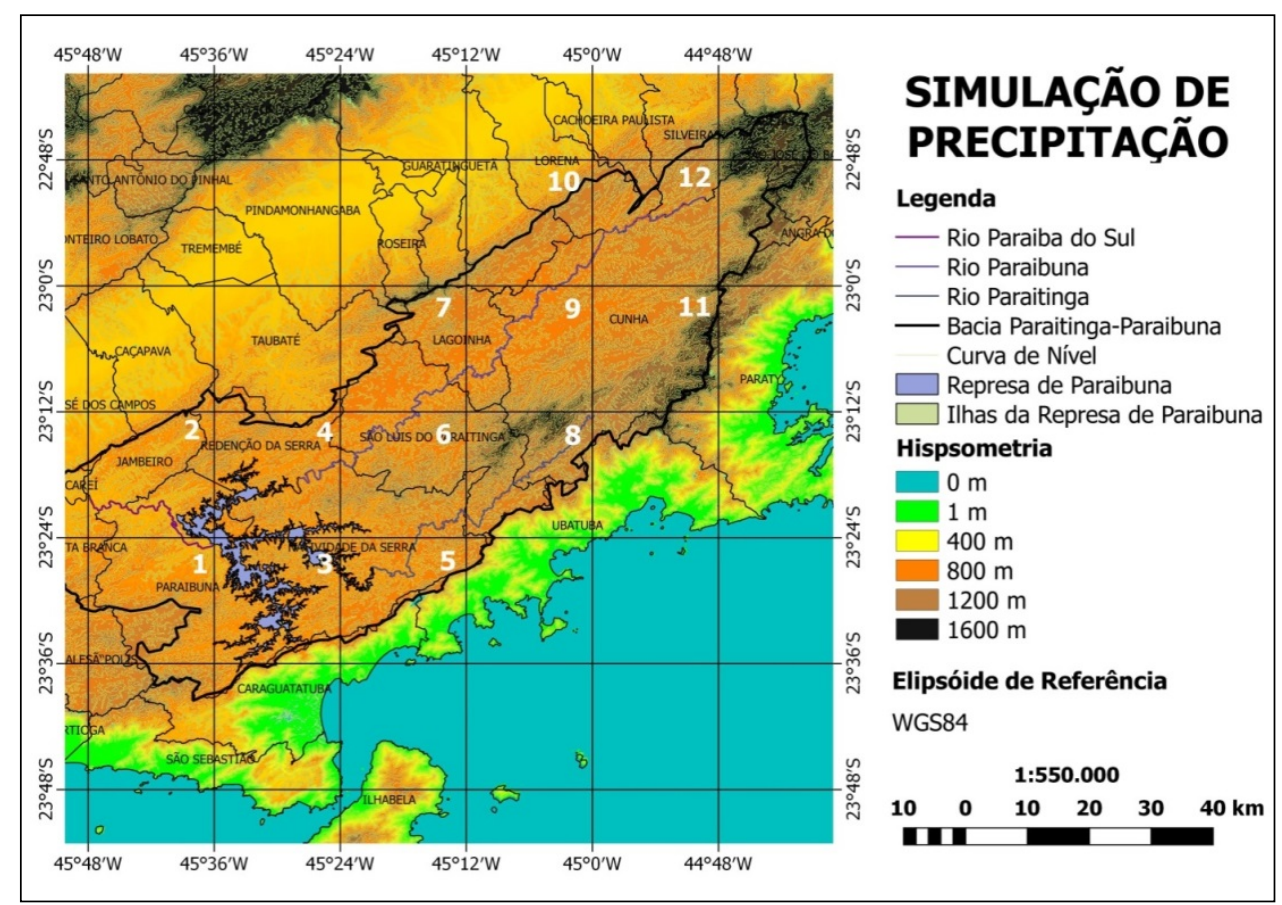

Figura 2. Mapa hipsométrico com indicação da grade de simulação de precipitação. 
Foram utilizados dois cortes temporais de simulação de dados, sendo um no período de 1961-1990 (denominado passado), e outro no período 2011-2040 (denominado futuro). Os dados simulados foram manipulados no aplicativo Microsoft Excel 2010, agrupados por ano, sendo obtido o valor total anual de precipitação para cada ano, média mensal de precipitação, precipitação máxima mensal, precipitação mínima mensal, média diária de precipitação e desvio padrão, com a finalidade de realizar uma previsão para os anos futuros.

Estimativa de uso da água e crescimento populacional

Para a previsão futura de crescimento de demanda do uso de água foi considerado o consumo médio da população por habitante de 180L/dia (VENDRAMEL et al., 2003). O crescimento populacional da região do Vale do Paraíba, onde se encontra a represa de Paraibuna, foi estimado a partir de dados observados da população e de seu respectivo crescimento anual, estas informações foram disponibilizadas pela Fundação Sistema
Estadual de Análise de Dados (SEADE).

\section{Estimativa futura de armazenamento de água na Represa de Paraibuna}

Para a interpretação dos dados passados e tendências futuras na represa de Paraibuna foram utilizados os métodos de coeficiente de correlação e regressão linear, pois estes permitem realizar previsões futuras e preencher lacunas a partir de períodos sem falhas de dados (SILVESTRE, 2016). Para tais cálculos foi considerada a capacidade útil disponível ao final do mês de março em relação ao total de precipitação durante o período chuvoso (abrangendo os meses de outubro a março) para os dados coletados da ANA (2017).

Isto permite que através de dados de precipitação simulados do futuro, aliada à estimativa de crescimento populacional e demanda pelas águas da represa de Paraibuna, estime-se a quantidade de água disponível para a represa ao final do período chuvoso e sua capacidade de deplecionamento durante o período de seca, demostrando os cenários futuros para a área de estudo.

\section{RESULTADOS E DISCUSSÃO}

Distribuição da precipitação na superfície da área de estudo

Os valores totais de precipitação para o período 1961-1990 indicam uma precipitação média anual de 1.363,1 mm. A média total de precipitação para o período chuvoso, que considera os meses de outubro a março foi de 959,5 mm e para o período de verão, que envolve os meses de dezembro a fevereiro de $485,8 \mathrm{~mm}$. Os dados obtidos a partir de simulação climática com o modelo HadCM3/Eta foram compatíveis com o resultado de outras pesquisas sobre a caracterização climática na região do Vale do Paraíba, a exemplo de Fisch (1995), Nunes \& Calbert (2000), Marengo \& Alves (2005), Villaron \& Fisch (2013) e Silva \& Simões (2014).

Para o período de 2011-2040, os valores observados indicam aumento do total anual de precipitação para $1.488,5 \mathrm{~mm}$ anuais. Os valores simulados para o período chuvoso mostram uma média de precipitação de 1.052,0 mm, enquanto que a média de precipitação para o período de verão foi de 544,0 mm. Santos \& Fisch (2016) ao analisar as precipitações passadas e tendências futuras de precipitação apenas para o município de Taubaté utilizando o modelo de simulação climática HadCM3/Eta encontraram resultados semelhantes à da presente pesquisa. Se comparada as precipitações simuladas do passado (base-line) com dados obtidos a partir de estação meteorológica localizada na Universidade de Taubaté, os valores de precipitação média foram subestimados em -1,6 mm para o período de 1961-1977, demostrando efetiva compatibilidade entre precipitação simulada e observada. Para o período 20112040, a precipitação observada por Santos \& Fisch (2016) foi de $1.542,0 \mathrm{~mm}$, valor compatível com o resultado apresentado pela presente pesquisa. Estes mesmos dados também são compatíveis com os resultados obtidos por Horikoshi \& Fisch (2007) e IPCC (2013).

Uma análise comparativa entre os períodos de 1961-1990 e 2011-2040 (Figura 3) indica que haverá um aumento na precipitação. As médias dos totais de precipitação mostram um acréscimo de 9,2\% nos valores entre o período passado (1961-1990) e futuro (2011-2040). Quando analisados separadamente, o período chuvoso (entre os meses de outubro a março) apresentou um aumento na precipitação de 9,6\% 
e o período de verão (entre os meses de demostrando uma tendência de maior dezembro a fevereiro) contará com um concentração das chuvas durante o período de acréscimo de $12 \%$ nos índices de precipitação, verão (Figura 3).

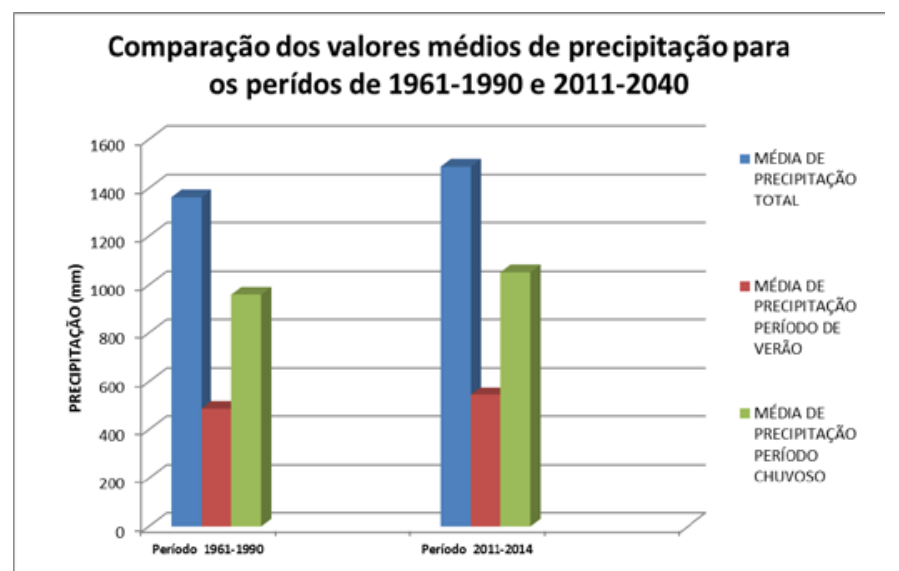

Figura 3. Comparação de precipitação média entre os períodos de 1961-1990 e 2011-2040

Os valores de precipitação ocorrem de maneira desigual em todo o sistema terrestre e na área de estudo desta pesquisa não é diferente. Para o período de 1961-1990, os índices de precipitação por ponto simulado indicam uma variação de até $74,1 \%$ para os totais anuais, sendo que para o período chuvoso essa diferença média pode chegar a $92,7 \%$ e para o período de verão este número é de 99,8\%, demostrando uma variabilidade espacial forte. Isto também já havia sido observado no estudo observacional realizado por Silva \& Simões (2014) para o Vale do Paraíba inteiro.

Os dados de precipitação demonstram que os pontos de simulação que possuem os maiores índices de precipitação são aqueles localizados nas áreas ao norte da área de estudo (Pontos 2, 6, 7 e 10), sendo que o Ponto 10 apresentou os maiores índices de precipitação com média anual de $1.704,6 \mathrm{~mm}$ e o Ponto 5 apresentou os menores índices com média anual de 979,0 mm. Os pontos 2, 6, 7 e 10 são áreas elevadas da região e demarcam o limite topográfico entre a área de captação de precipitação direta do rio Paraibuna e do Paraíba do Sul, ainda que ambos os rios formem a mesma bacia hidrográfica. Estes dados de precipitação indicam que há uma interferência direta das formas geográfica e altitude do relevo regional na distribuição da precipitação ao longo da área de estudo, através das chuvas orográficas.

Para o período 2011-2040 os valores médios de precipitação simulados indicam uma variação dos índices de chuva entre os pontos de até 77,9\%, sendo que para o período chuvoso esta variação pode atingir $96,5 \%$ e para o período de verão de 96,7 (Tabela 1). Comparando-se quanto aos pontos de simulação onde ocorrem os maiores índices de precipitação entre os períodos de 19611990 e de 2011-2040, pode-se observar que os locais se mantêm praticamente o mesmo, alterando-se apenas as posições dos pontos de simulação 4 e 9 para o período 2011-2040, sendo muito pequena esta variação (inferior a $2 \mathrm{~mm}$ ).

Tabela 1. Média de precipitação por período e ponto simulado.

\begin{tabular}{|c|c|c|c|c|c|c|}
\hline \multirow[b]{2}{*}{$\begin{array}{c}\text { Médias de } \\
\text { precipitação }\end{array}$} & \multicolumn{3}{|c|}{ Período 1961-1990 } & \multicolumn{3}{|c|}{ Período 2011-2040 } \\
\hline & $\begin{array}{c}\text { Período chuvoso } \\
(\mathrm{mm})\end{array}$ & $\begin{array}{c}\text { Período de } \\
\text { verão }(\mathrm{mm})\end{array}$ & Total (mm) & $\begin{array}{c}\text { Período chuvoso } \\
(\mathrm{mm})\end{array}$ & $\begin{array}{c}\text { Período de } \\
\text { verão }(\mathrm{mm})\end{array}$ & $\begin{array}{l}\text { Total } \\
(\mathrm{mm})\end{array}$ \\
\hline PONTO 1 & 858,4 & 434,4 & 1253,8 & 940,3 & 494,1 & 1362,3 \\
\hline PONTO 2 & 1129,3 & 580,9 & 1580,9 & 1253,2 & 655,3 & 1739,5 \\
\hline PONTO 3 & 785,0 & 394,6 & 1155,2 & 858,0 & 449,9 & 1254,0 \\
\hline PONTO 4 & 1006,9 & 517,1 & 1427,6 & 1114,6 & 586,5 & 1561,8 \\
\hline PONTO 5 & 649,5 & 320,4 & 979,0 & 693,8 & 354,4 & 1054,2 \\
\hline PONTO 6 & 1034,0 & 528,9 & 1481,9 & 1138,3 & 598,7 & 1608,9 \\
\hline PONTO 7 & 1083,3 & 556,3 & 1504,3 & 1193,3 & 611,6 & 1650,2 \\
\hline PONTO 8 & 728,6 & 356,8 & 1070,6 & 782,8 & 398,0 & 1151,9 \\
\hline PONTO 9 & 1009,6 & 508,3 & 1426,2 & 1112,8 & 568,7 & 1562,2 \\
\hline PONTO 10 & 1251,7 & 640,3 & 1704,6 & 1365,1 & 696,6 & 1875,8 \\
\hline PONTO 12 & 1018,5 & 505,4 & 1409,8 & 1119,4 & 570,5 & 1553,0 \\
\hline $\begin{array}{l}\text { MÉDIA } \\
\text { GERAL }\end{array}$ & 959,5 & 485,8 & 1363,1 & 1052,0 & 544,0 & 1488,5 \\
\hline
\end{tabular}


Estes resultados corroboram com aqueles apontados por Silva \& Simões (2014), que ao analisar a distribuição espacial da precipitação na região do Vale do Paraíba, apontam a grande variabilidade interanual de chuvas e sua concentração nas áreas mais elevadas da região, com destaque para a Serra da Mantiqueira (com altitudes que atingem $2400 \mathrm{~m}$ ) e Serra da Bocaina (com atitudes de $1400 \mathrm{~m}$ ). Apontam ainda que os menores índices de precipitação estão localizados nas áreas mais baixas da região, com altitudes que variam de 540 a $780 \mathrm{~m}$ de altitude.

Os dados da pesquisa indicam uma tendência futura de manutenção dos maiores índices de precipitação nas regiões de altitudes elevadas, reforçando a hipótese da interferência do relevo na distribuição da precipitação. Fica evidente que as vertentes a barlavento na Serra no Mar nos municípios de Ubatuba, Caraguatatuba, São Sebastião, Bertioga, Salesópolis e mesmo em Paraibuna interferem diretamente na umidade atmosférica dessas massas de ar provenientes do Oceano Atlântico, sendo que quando estas ultrapassam esses maciços montanhosos, chegam mais secas nas vertentes opostas, a sotavento, diminuindo a precipitação nestas áreas (Pontos 1, 3, 5, 8 e 12). Estes pontos 1, 3, 5 , 8 e 12 sofrem influência do fenômeno denominado sombra de chuvas ou sombra de precipitação, sendo uma área de precipitação reduzida em função de chuvas orográficas à barlavento das vertentes montanhosas. As elevações topográficas ao sul da represa, destacando-se a Serras dos Monos, Serra dos Sete Ratis, Serra dos Remédios e Serra do Marais são as elevações do relevo responsáveis pela existência da sombra de precipitação ao sul da represa de Paraibuna.

Precipitação e porcentagem de volume útil disponível na Represa de Paraibuna: Passado e tendências futuras

O período entre os anos 1983-2002 (dados disponíveis de Cezário, 2005) a comparação entre o total de precipitação durante o período chuvoso (outubro a março) e a quantidade de água disponível ao final do mesmo período (em março) apresentou um baixo índice de correlação $(\mathrm{R}=0,6100)$. Esta baixa correlação entre os dados analisados justifica-se pelo fato de que neste período, a quantidade de chuva durante o período chuvoso foi comparada com a média de água disponível na represa durante o mês de março.

Para o período 2012-2016, os dados apresentaram forte correlação entre a quantidade de precipitação ocorrida na área de estudo e a disponibilidade de água na represa de Paraibuna $(\mathrm{R}=0,9993)$. Este melhor resultado justifica-se pelo fato que a precipitação durante o período chuvoso foi comparada à disponibilidade de água na represa de Paraibuna no último dia do período chuvoso (Figura 4).

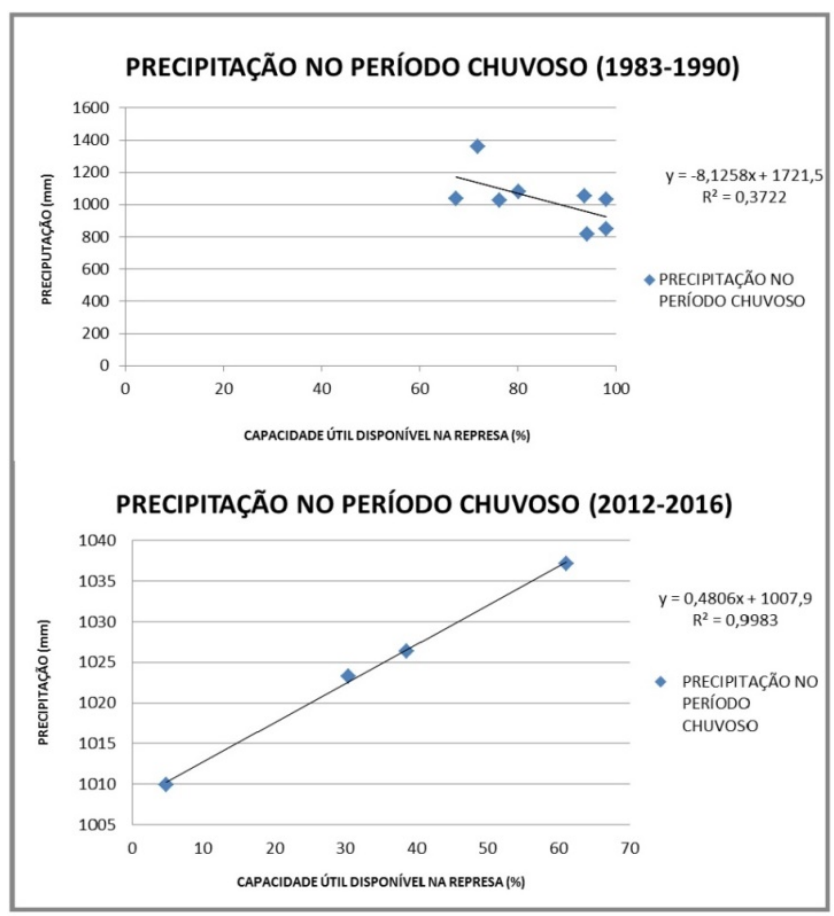

Figura 4. Relação entre precipitação no período chuvoso e capacidade armazenada de água na represa de Paraibuna nos períodos de 1983-1990 e 2012-2016. 
A forte correlação obtida entre precipitação durante o período chuvoso e quantidade de água disponível na represa de Paraibuna permite a previsão futura da capacidade de água disponível na represa de Paraibuna conhecendo os valores de precipitação, que foram obtidos pelo modelo de simulação climática regionalizado HadCM3/Eta (Tabela 2).

Tabela 2. Relação entre precipitação e capacidade de armazenamento na represa de Paraibuna.

\begin{tabular}{lccccc}
\hline Ano & Precipitação $(\mathbf{m m})$ & Capacidade (\%) & Ano & Precipitação $(\mathbf{m m})$ & Capacidade (\%) \\
\hline 2017 & 1071,9 & 46,9 & 2029 & 869,3 & 11,9 \\
2018 & 1156,6 & 53,5 & 2030 & 1292,1 & 75,7 \\
2019 & 1130,3 & 52,0 & 2031 & 963,7 & 26,2 \\
2020 & 945,2 & 22,3 & 2032 & 751,7 & $-5,8$ \\
2021 & 925,3 & 20,7 & 2033 & 961,7 & 25,9 \\
2022 & 1127,3 & 51,4 & 2034 & 970,5 & 27,2 \\
2023 & 1273,7 & 72,6 & 2035 & 869,7 & 12,0 \\
2024 & 1199,6 & 61,9 & 2036 & 934,9 & 21,9 \\
2025 & 948,4 & 23,7 & 2037 & 939,5 & 22,5 \\
2026 & 951,1 & 24,5 & 2038 & 934,2 & 21,7 \\
2027 & 1321,3 & 80,1 & 2039 & 1480,8 & 104,2 \\
2028 & 990,6 & 30,2 & 2040 & 1167,0 & 56,9 \\
\hline
\end{tabular}

Os dados de capacidade útil futuros da represa de Paraibuna em função das precipitações simuladas demonstram que o ano de 2032 merece destaque, uma vez que o nível simulado de capacidade útil da represa neste ano será de $-5,8 \%$. Isto indica que a represa atingirá sua reserva técnica (volume morto) e que haverá a necessidade de utilizá-la para continuar a atender às demandas por suas águas, tal como ocorreu como o sistema Canteira e a Represa de Paraibuna durante a crise hídrica de 2014-2015, quando o mesmo foi autorizado por Resoluções (Resolução Conjunta ANA- Agência Nacional de Águas DAEE- Departamento de Águas e Esgoto do Estado de São Paulo nº 910, Resolução Conjunta ANA/DAEE n ${ }^{\circ} 1672$ e Resolução Conjunta ANA-DAEE $n^{\circ} 151$ ) e por Comunicado Conjunto ANA-DAEE $n^{\circ} 233$ (ANA, 2015).

A média de armazenamento na represa de Paraibuna ao final do período chuvoso será de 39,2\%, com destaque para o ano 2039 quando o mesmo atingirá $104,2 \%$, volume acima se sua capacidade máxima, algo que ocorreu pela última vez em 2010 (Tabela 2).

Comportamento da represa durante o período de estiagem e delimitação de capacidade de transposição de águas

Os períodos disponíveis que possuem dados de precipitação e porcentagem útil disponível na represa (1983-2002 e 2006-2016) demostraram que há uma variabilidade quanto à capacidade útil de água disponível ao final do período de estiagem, que envolve o primeiro dia do mês de abril, quando se encerra o período chuvoso, até o último dia de setembro do mesmo ano, quando tem início novamente o período chuvoso (Tabela 3). Segundo Fisch (1999), a estação chuvosa na região inicia-se na segunda quinzena de outubro de cada ano, resultado semelhante ao apontado por Calbete et al. (2006).

No período 1983-2002 o valor médio de perda na capacidade de armazenamento útil da represa de Paraibuna foi de -6,3\%. Em apenas sete anos estas diferenças foram positivas (1983, 1985, 1986, 1987, 1991 e 1995), havendo neste caso uma recuperação média de $11,2 \%$ da capacidade de armazenamento da represa. Por outro lado, para o mesmo período, em treze anos houve um decréscimo na capacidade útil disponível, sendo o valor médio do mesmo de $-12,5 \%$.

Para o período 2006-2016 a média de perda de armazenamento útil da represa foi de -13,9\%, sendo que em dois anos houve variação positiva (2008 e 2016), gerando neste caso uma recuperação média de 7,2\%. Em nove anos houve decréscimo na capacidade de armazenamento da represa, sendo o mesmo de $-18,6 \%$. Nos dois períodos analisados o consumo de água da população da região do Vale do Paraíba e suas atividades econômicas já estão inseridas no deplecionamento da represa durante o período seco do ano, salientando-se que, ao longo dos anos de 2015 e 2016, ocorreram campanhas educativas para a redução de consumo de água.

Dados da SEADE (2017), apontam que a população da região administrativa de São José dos Campos, que envolve o Vale do Paraíba, local de estudo da pesquisa, em 1983 era de 
Tabela 3. Relação entre período de estiagem e condição de armazenamento da represa de Paraibuna entre 1983-2016 quanto ao início e fim do período chuvoso.

\begin{tabular}{cccc}
\hline Ano & $\begin{array}{c}\text { Diferença de } \\
\text { porcentagem útil da } \\
\text { represa (\%) }\end{array}$ & Ano & $\begin{array}{c}\text { Diferença de } \\
\text { porcentagem útil da } \\
\text { represa (\%) }\end{array}$ \\
\hline 1983 & 30,6 & 1999 & $-0,6$ \\
1984 & $-20,0$ & 2000 & $-14,8$ \\
1985 & 6,0 & 2001 & $-25,5$ \\
1986 & 2,1 & 2002 & $-2,4$ \\
1987 & 1,3 & 2006 & $-26,9$ \\
1988 & $-7,7$ & 2007 & $-34,5$ \\
1989 & $-6,1$ & 2008 & 4,5 \\
1990 & $-6,1$ & 2009 & $-1,1$ \\
1991 & 17,4 & 2010 & $-26,2$ \\
1992 & $-24,7$ & 2011 & $-13,5$ \\
1993 & 4,9 & 2012 & $-19,3$ \\
1994 & $-1,1$ & 2013 & $-11,7$ \\
1995 & 9,8 & 2014 & $-30,3$ \\
1996 & $-7,8$ & 2015 & $-3,9$ \\
1997 & $-13,8$ & 2016 & 10,0 \\
1998 & $-25,7$ & & \\
\hline
\end{tabular}

1.320.421 habitantes, tendo chegado a 2.404.276 hab. no ano de 2016. A Fundação SEADE aponta que o crescimento populacional entre 2010-2016 foi de $1 \%$ ao ano e que a população prevista para o ano de 2030 é estimada de 2.632.763 hab. Considerando que se mantenha a taxa de crescimento populacional de 1\% a.a., em 2040 a população total prevista para a região do Vale do Paraíba será de 2.908.208 hab.

Ao considerar um valor médio de consumo de água por habitante da região do Vale do Paraíba de 180 L/dia (VENDRAMEL et al.,

2003) e seu respectivo aumento anual devido ao crescimento da população, aliado à transposição das águas da represa de Jaguari, pertencente à bacia do Rio Paraíba do Sul para a represa de Atibainha, pertencente à bacia do Rio Piracicaba no valor de $5,13 \mathrm{~m}^{3} \mathrm{~s}^{-1}$ (ANA, 2015), haverá um aumento gradual na demanda por água até 2040 de 123,4\% (Tabela 4). As obras de transposição entre as represas já estão finalizadas, sendo que em janeiro de 2017 encontravam-se 46\% concluídas, aumentando para $80 \%$ em julho do mesmo e concluídas em março de 2013 (SÃO PAULO, 2017; SÃO PAULO, 2018).

Tabela 4. Evolução da demanda diária por água na região administrativa de São José dos Campos (Vale do Paraíba Paulista).

\begin{tabular}{ccccc}
\hline Ano & População & Transposição & $\begin{array}{c}\text { Consumo da } \\
\text { população }\end{array}$ & Total \\
\hline 2016 & 2.404 .276 & - & $432.769,68 \mathrm{~m}^{3}$ & $432.769,68 \mathrm{~m}^{3}$ \\
2040 & 2.908 .208 & $443.232,00 \mathrm{~m}^{3}$ & $523.477,44 \mathrm{~m}^{3}$ & $966.709,44 \mathrm{~m}^{3}$ \\
$\begin{array}{c}\text { Diferença entre } \\
\text { 2016-2040 (\%) }\end{array}$ & $21,0 \%$ & - & $21,0 \%$ & $123,4 \%$ \\
\hline
\end{tabular}

a) Desta forma, considera-se: i) que Resolução Conjunta ANA/DAEE/IGAM/INEA n ${ }^{0} 1.382$ de 2015 (ANA, 2015) indica que a represa de Paraibuna deve operar com, no mínimo, 5\% de sua capacidade útil; ii) que haverá um aumento pela demanda de água na região de $123,4 \%$; iii) que a perda média de capacidade de armazenamento da represa durante o período seco nos anos que houve decréscimo de sua capacidade útil foi de $-15,5 \%$, estabelecem-se os seguintes parâmetros para a capacidade de transposição de águas entre as bacias hidrográficas em questão: Acima de 39,6\% de capacidade útil disponível: Pode ocorrer a transposição das águas entre a Bacia do Rio Paraíba do Sul e o Sistema Cantareira;

b) Abaixo de 39,6\% de capacidade útil disponível: não pode ocorrer a transposição das águas em função do deplecionamento da represa e da demanda ocasionar uma disponibilidade da útil da represa inferior a 5\%. Para o estabelecimento deste índice foi considerada a média dos anos em que 
houve deplecionamento da represa nos períodos 1983-2002 e 2006-2016 (a perda média de capacidade útil da represa foi de$15,5 \%$, acrescidos o aumento na demanda de $123,4 \%$ ) e por fim os $5 \%$ de capacidade útil mínima disponível da represa estabelecida pela Resolução Conjunta ANA/DAEE/ IGAM/INEA $n^{0} 1.382$ de 2015 (ANA, 2015), totalizando uma disponibilidade útil mínima da represa de $39,6 \%$, conforme pode ser observado na Figura 5.

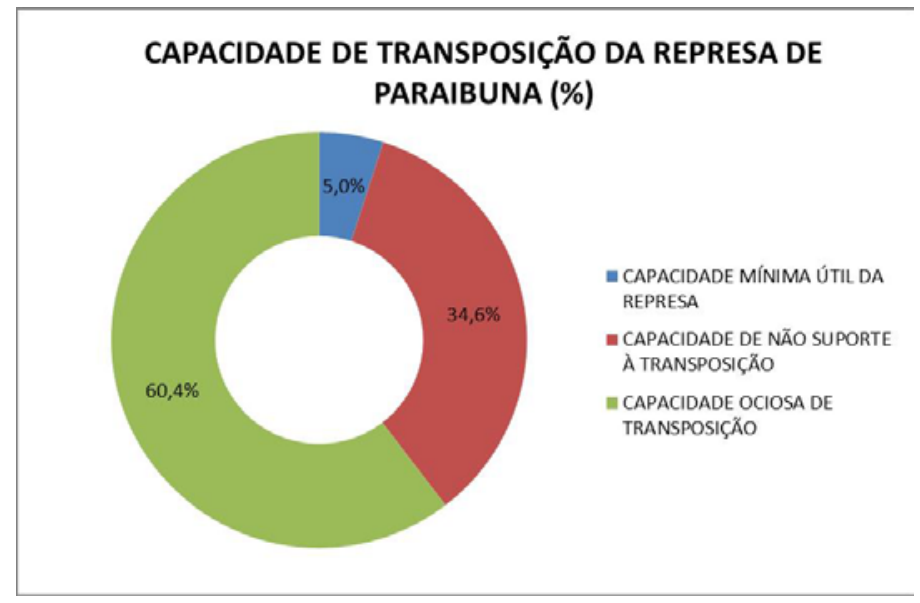

Figura 5. Relação entre a capacidade útil armazenada de água na represa de Paraibuna e sua capacidade de transposição.

Os parâmetros acima definidos, aliados aos valores futuros previstos de precipitação e sua respectiva capacidade útil disponível apontam que (Tabela 2):

a) Até o ano de 2040 em 14 anos (2020, 2021, 2025, 2026, 2028, 2029, 2031, 2032, 2033, 2034, 2035, 2036, 2037 e 2038) não haverá a possibilidade de ocorrer a transposição das águas da bacia do Rio Paraíba do Sul para o Sistema Cantareira, devido ao fato que o estoque de água disponível na represa após o período chuvoso ser inferior a $39,6 \%$ de sua capacidade. Quando o estoque útil disponível é inferior ao valor supracitado, o deplecionamento da represa durante o período seco ocasionará um estoque de capacidade útil da represa inferior a 5\%, o que não pode ocorrer de acordo com a Resolução Conjunta ANA/DAEE/IGAM/ INEA n ${ }^{\circ} 1.382$ de 2015 (ANA, 2015).

b) Até o ano de 2040 em 10 anos (2017, 2018,
2019, 2022, 2023, 2024, 2027, 2030, 2039, 2040) poderá ocorrer a transposição das águas da Bacia do Rio Paraíba do Sul para o Sistema Cantareira, fato que se justifica pelo estoque disponível ao final do período chuvoso que suporta o deplecionamento da represa durante o período seco, sem atingir índices inferior a 5\% de sua capacidade útil.

As condições acima descritas para a ocorrência da transposição considera a capacidade útil da represa de Paraibuna como referência, uma vez que a mesma é integrante do reservatório equivalente de água do Sistema Paraíba do Sul (formado pelas represas de Paraibuna, Santa Branca, Jaguari e Funil) e que seu volume total disponível e útil representa, respectivamente, $\quad 73,8$ e $70,5 \%$ da disponibilidade de água considerando as represa de Paraibuna, Santa Branca, Funil e Jaguari, sendo que esta última será onde ocorrerá a transposição.

\section{CONCLUSÃO}

Os dados simulados de precipitação e sua distribuição espacial indicam a possibilidade de ocorrência do fenômeno sombra de precipitação na região, não alterando a distribuição espacial dos volumes de chuva na região para os períodos analisados (1961-1990 e 2011-2040).

Os resultados apontam ainda que os volumes de precipitação futuros aliados ao aumento na demanda pelas águas da região do
Vale do Paraíba (resultados da transposição entre as bacias do rio Paraíba do Sul e de seu respectivo aumento populacional) tornará possível a transferência de água entre a bacia do rio Paraíba do Sul para o Sistema Cantareira em apenas $40 \%$ dos anos até 2040, sendo que ao longo da década de 2030 a transposição poderá ocorrer em apenas três anos, demostrando a baixa efetividade da proposta (30\% apenas). 


\section{REFERÊNCIAS}

ANA. Agência Nacional de Águas. Relatório Conjunto de interligação Jaguari-Atibainha (2015). Disponível em: $<$ http://www2.ana.gov.br/Paginas/servicos/saladesituacao/v2/ RioParaibadoSul.aspx>. Acesso em: 25 de novembro de 2017.

ANA. Agência Nacional de Água. Bacia do rio Paraíba do Sul (2017). Disponível em: <http://www2.ana.gov.br/Paginas/ servicos/saladesituacao/v2/RioParaibadoSul.aspx>. Acesso em: 20 de março de 2017.

ANJOS, M. \& FERREIRA, M.B. Aurélio século XXI: o dicionário da língua portuguesa. 3. ed. Rio de Janeiro: Nova Fronteira, 1999.

CALBETE, N.O.; LIRA, A.C.; SANSIGOLO, C.A. Estimativas do início da estação chuvosa no Vale do Paraíba e litoral norte de São Paulo. In: XIV Congresso Brasileiro de Meteorologia, Florianópolis: Sociedade Brasileira de Meteorologia, 2006.

CARVALHO, R.C. Gestão dos Recursos Hídricos: conflito e negociação da questão das águas transpostas na Bacia do Paraíba do Sul. 237p. 2005. Tese de Doutorado. Tese de Doutorado em Ciências e Planejamento Energético. Curso de Pós-Graduação em Engenharia. Universidade Federal do Rio de Janeiro. Rio de Janeiro.

CEZÁRIO, M.V. Um estudo sobre a influência da precipitação regional do Vale do Paraíba no nível de água do reservatório de Paraibuna. 106 p. Dissertação (Mestrado em Ciências Ambientais) - Departamento de Ciências Agrárias, Universidade de Taubaté, Taubaté, 2005.

COLLISCHONN, B. \& CLARKE, R. T. Estimativa e incerteza de curvas cota-volume por meio de sensoriamento remoto. Revista Brasileira de Recursos Hídricos, Porto Alegre, v. 21, n. 4, p. 719-727, out./dez. 2016

FISCH, G. Caracterização climática e balanço hídrico de Taubaté (SP). Revista Biociências, Taubaté, v. 1, n. 1, p. 8190, 1995.

FISCH, G. Distribuição da precipitação em Taubaté, Vale do Paraíba (SP). Revista Biociências, Taubaté, v. 5, n. 2, p. 7-11, 1999.

GOHARI, A.; ESLAMIAN, S.; MIRCHI, A.; ABEDIKOUPAEI, J.; BAVANI, A.M.; MADANI, K. Water transfer as a solution to water shortage: A fix that can Backfire. Journal of Hydrology, n.491, p. 23-39, 2013.

GRIFFIN, D. \& ANCHUKAITIS, K.J. How unusual is the 2012-2014 California drought? Geophyical Research Letter, n.41, p. 9017-9023, 2014.

HORIKOSHI, A.S. \& FISCH, G.F. Balanço hídrico atual e simulações para cenários climáticos futuros no município de Taubaté, SP, Brasil. Ambi-Água, Taubaté, v.2, n.2, p. 3346, 2007.

INPE. Instituto Nacional de Pesquisas Espaciais. Veja 5 perguntas sobre o Cantareira; gráfico mostra evolução de reserva. Disponível em: <http://www.ccst.inpe.br>. Acesso em: 27 de agosto de 2015.

IPCC. Intergovernmental Panel on Climate Change. Fifth Assessment Report "Climate change 2013: The physical Science basis”, 2013. Disponível em: < http://www.ipcc.ch> acesso em 15 de julho de 2015.

JACOBI, P. R.; CIBIM, J.; LEÃO, R. S. Crise hídrica na Macrometrópole Paulista e respostas da sociedade civil. Estudos avançados, v. 29, n. 84, p. 27-42, 2015.

MARENGO, J.A. \& ALVES, L.M. Tendências hidrológicas da bacia do rio Paraíba do sul. Revista Brasileira de Meteorologia, v.20, n.2, p.215-226, 2005.

MARENGO, J. A. \& ALVES, L. M. Crise hídrica em São Paulo em 2014: seca e desmatamento. GEOUSP: Espaço e Tempo (Online), v. 19, n. 3, p. 485-494, 2015a.
MARENGO, J.A.; NOBRE, C.A.; SELUCHI, M.E.; CUARTAS, A.; ALVES, L.M.; MEDIONDO, E.M.; OBREGÓN, G.; SAMPAIO, G. A seca e a crise hídrica de 2014-2015 em São Paulo. Revista USP, n. 106, p. 31-44, 2015b.

MATTOSO, S.Q. Transposição do Rio São Francisco: Uma Avaliação. Revista Intertox de Toxicologia, Risco Ambiental e Sociedade, v. 2, n. 3, 2009.

NUNES, L.H. \& CALBET, N.O. Variabilidade pluviométrica no Vale do Paraíba Paulista. In: Congresso Brasileiro de Meteorologia. Rio de Janeiro: Sociedade Brasileira de Meteorologia, 2000. p. 3987-3994

OLIVEIRA FILHO, G.R. A crise da água na região Metropolitana de São Paulo em 2014 e a ineficiente gestão dos recursos hídricos. CES REVISTA, Juiz de Fora, v. 29, n. 1. p. 5 -20, jan./jul. 2015.

SANTOS, T.A. \& FISCH, G. Temperatura e precipitação: futuros cenários do município de Taubaté, SP, Brasil. Ambiente e Água, v. 11, n. 5, p. 1068-1087, 2016.

SÃO PAULO. Interligação Jaguari-Atibainha tem $\mathbf{8 0} \%$ de obras concluídas. Disponível em: http://www.saopaulo. sp.gov.br/spnoticias/interligacao-jaguari-atibainha-tem-80-deobras-concluidas-com-encontro-de-tuneis/. Acesso em: $28 \mathrm{de}$ agosto de 2017.

SÂO PAULO. Alckmin inaugura obra que amplia segurança hídrica em SP e no RJ. Disponível em: http://www.saopaulo.sp.gov.br/spnoticias/ultimas-noticias/ alckmin-inaugura-obra-que-amplia-seguranca-hidrica-em-spe-no-rj/. Acesso em: 20 de junho de 2018.

SEADE. Fundação Sistema Estadual de Análise de Dados. Informação dos municípios paulistas. Disponível em: $<$ http://www.imp.seade.gov.br/frontend/\#/>. Acesso em: 25 de março de 2017.

SILVA, W.M. \& SIMÕES, S.J.C. Spatial Intra-Annual Variability of Precipitation Based on Geostatistics. A Case Study for the Paraba Do Sul Basin, Southeastern Brazil. International Journal of Geosciences, 5, p. 408-417, 2014.

SILVESTRE, M. R. Técnicas estatísticas utilizadas em climatologia geográfica: diagnóstico e propostas. 2016. 408p. Tese de Doutorado em Geografia. Universidade Estadual Paulista, Presidente Prudente.

VENDRAMEL, E.; MENDES, C.M.; KOHLER, V.B. Considerações sobre os serviços de água na produção do espaço Urbano de Maringá-PR. GEOGRAFIA LONDRINA - V. 12 - N. 2 - JUL./DEZ.2003.

VILLARON, M.A. \& FISCH, G. Caracterização do início do período chuvoso no Vale do Paraíba Paulista. Ambiente e Água. Taubaté, vol. 8 (suplementos), p.38-49, 2013.

WILSON, M.C.; LI, X. .; MA, Y.J.; SMITH, A.T.; WU, J.A. Review of the Economic, Social, and Environmental Impacts of China's South-North Water Transfer Project: A Sustainability Perspective. Sustainability9, no. 8: 1489, 2017. 